IZA DP No. 6467

Cultural Integration: Experimental Evidence of Changes in Immigrants' Preferences

Lisa Cameron

Nisvan Erkal

Lata Gangadharan

Marina Zhang

April 2012 


\title{
Cultural Integration: \\ Experimental Evidence of Changes in Immigrants' Preferences
}

\author{
Lisa Cameron \\ Monash University \\ and IZA \\ Nisvan Erkal \\ University of Melbourne \\ Lata Gangadharan \\ Monash University \\ Marina Zhang \\ University of Melbourne
}

\section{Discussion Paper No. 6467 \\ April 2012}

IZA
P.O. Box 7240
53072 Bonn
Germany
Phone: +49-228-3894-0
Fax: +49-228-3894-180
E-mail: iza@iza.org

\begin{abstract}
Any opinions expressed here are those of the author(s) and not those of IZA. Research published in this series may include views on policy, but the institute itself takes no institutional policy positions.

The Institute for the Study of Labor (IZA) in Bonn is a local and virtual international research center and a place of communication between science, politics and business. IZA is an independent nonprofit organization supported by Deutsche Post Foundation. The center is associated with the University of Bonn and offers a stimulating research environment through its international network, workshops and conferences, data service, project support, research visits and doctoral program. IZA engages in (i) original and internationally competitive research in all fields of labor economics, (ii) development of policy concepts, and (iii) dissemination of research results and concepts to the interested public.
\end{abstract}

IZA Discussion Papers often represent preliminary work and are circulated to encourage discussion. Citation of such a paper should account for its provisional character. A revised version may be available directly from the author. 


\section{ABSTRACT \\ Cultural Integration: Experimental Evidence of Changes in Immigrants' Preferences}

Cultural traits play a significant role in the determination of economic outcomes and institutions. This paper presents evidence from laboratory experiments on the cultural integration of individuals of Chinese ethnicity in Australia, focusing on social preferences, preferences for competition, and risk attitudes. We show that the greater the share of education an individual receives in the West, the more they behave like Western subjects and the less they behave according to the norms of their Eastern heritage. Increased exposure to Western education has a strong negative impact on altruism, trust, and trustworthiness. For risk and competitive preferences, our results are gender-specific. These results have important implications for policy making and institution building in multi-cultural societies.

JEL Classification: C91, J15, D64, D03

Keywords: cultural integration, cultural transmission, cultural diversity, cultural assimilation, acculturation, immigration, social preferences, preferences for competition, risk aversion

Corresponding author:

Lisa Cameron

Department of Econometrics

Monash University

VIC 3800

Australia

E-mail: lisa.cameron@monash.edu

\footnotetext{
* We would like to thank Sherry Li, Tom Wilkening, and seminar participants at University College London for helpful comments. We thank the Australian Research Council, and the Faculty of Business and Economics at the University of Melbourne for their financial support.
} 


\section{Introduction}

Social preferences, preferences for competition, and risk attitudes vary significantly across cultures $^{3}$ (see, e.g., Henrich et al., 2005; Holm and Danielson, 2005; Buchan et al., 2006; Alesina and Giuliano, 2011; Luttmer and Singhal, 2011). This paper seeks to examine how these cultural traits evolve over time when members of one culture move to a country with a distinctly different culture. Do we see a persistence of cross-cultural differences or a convergence to the traits of the host country?

Cultural traits play a significant role in the determination of economic outcomes (see, e.g., Guiso et al., 2006). They are also important in shaping the economic, political, and social institutions of a society. For example, Algan and Cahuc (2009) show the impact of civic virtue on labor market institutions (the provision of unemployment benefits), Alesina et al. (2010) study the influence of family values on labor market regulations, and Alesina and Giuliano (2011) examine how family values affect political participation. Policy makers are actively interested in how best to design policies that encourage cultural integration and harmony. Such policies may take the shape of, for example, strict citizenship tests or changes in educational curriculum. Effective policy making requires a good understanding of the rate and process of cultural integration.

In the economics literature, a lot of attention has been given to the economic integration of immigrants. There exists a recent but fast-growing literature on the cultural integration patterns of different immigrant groups. Studies of the behavior of immigrants have shown that the speed with which cultural values evolve over time depends on the context and the cultural value under consideration. See, for example, Manning and Roy (2005), Bisin et al. (2008), and Constant and Zimmermann (2008) on ethnic identity,

\footnotetext{
${ }^{3}$ By culture, we refer to "those customary beliefs and values that ethnic, religious, and social groups transmit fairly unchanged from generation to generation" (Guiso et al., 2006).
} 
Fernandez and Fogli (2009) on fertility, Algan and Cahuc (2010) on trust, de Palo et al. (2007) on social relations, Guiso et al. (2006), Alesina and Fuchs-Schuendeln (2007) and Luttmer and Singhal (2011) on preferences for redistribution, and Giuliano (2007) on living arrangements.

Our paper contributes to this literature by considering cultural integration along the dimensions of social preferences (altruism, trust, and trustworthiness), preferences for competition, and risk attitudes. Cultural integration along these dimensions have generally not been analysed in the literature. One exception is Algan and Cahuc (2010). They focus on the transmission of trust within families and show a statistically significant correlation between inherited trust of the descendants of US immigrants and trust in their country of origin. In other related work, Guiso et al. (2006), Alesina and FuchsSchuendeln (2007), Alesina and Giuliano (2011), and Luttmer and Singhal (2011) focus on preferences for redistribution. ${ }^{4}$ All of these papers use survey data to examine cultural integration.

We present evidence from laboratory experiments conducted with participants of Chinese ethnicity in Australia. Each subject participated in a Dictator Game, a Trust game, a Risk Game, and a Competition Game. To evaluate how preferences and behavior change over time, we conducted the experiments with participants who had varying degrees of exposure to Australian culture.

To assess the degree of cultural integration, we consider the impact of exposure to Western education (the share of one's education gained in Australia) on the subjects'

\footnotetext{
${ }^{4}$ Guiso et al. (2006), Alesina and Giuliano (2011), and Luttmer and Singhal (2011) find evidence of a lasting effect of culture using data from the General Social Survey in the U.S., World Values Survey, and the European Social Survey. Alesina and Fuchs-Schuendeln (2007) investigate preferences for redistribution among East and West Germans. They find that, after German reunification, East Germans are more in favor of redistribution than West Germans, but that East Germans' preferences converge towards those of West Germans.
} 
behavior in the four games mentioned above. Focusing on the impact of exposure to Western education (as opposed to, for example, the percentage of one's lifetime spent in a Western country) is important for two reasons. First, it is a more direct measure of the amount of exposure immigrants have to the cultural traits of the host country than the percentage of one's lifetime spent in a Western country. It is possible for immigrants to spend a considerable portion of their life in the host country but to interact mainly with their own ethnic group, in which case they have only minimal exposure to the institutions and culture of their new home. Second, examining the impact of exposure to Western education allows us to explore the role educational institutions have in immigrationrelated policy making.

Our results reveal that education does indeed play an important role in cultural integration. In all games, we find evidence of subjects' behavior more closely reflecting Australian norms of behavior, the more exposure the subjects have had to Western education. Specifically, greater exposure to Western education significantly decreases giving in the Dictator and Trust games. It also significantly decreases the amount returned in the Trust game. Hence, it has a significant and negative impact on altruism, trust, and trustworthiness. The impact on risk attitudes is gender-specific. While greater exposure to Western education makes women more risk-loving, it does not have a significant impact on the risk-taking behavior of men. Finally, exposure to Western education does not change the willingness of men to engage in competition, but it does decrease women's confidence and consequently their willingness to compete.

In the experimental literature, although some papers have studied cross-cultural differences, how cultural traits evolve in multi-cultural settings has been largely ignored. A couple of recent papers have studied cultural differences between migrants and non- 
migrants. Chen et al. (2010) show that participants from ethnic minority and majority populations respond differently to priming (i.e., the process of highlighting the salience of different social identities), with Asian students being more responsive to priming than Caucasian students. In contrast, we investigate how behaviour changes with varying exposure to Western culture. Guillen and $\mathrm{Ji}$ (2011) examine trust and patterns of discrimination between international (Asian) students and domestic (Australian) students. Senders in the Trust game are informed of the cultural identity and ability (ascertained by a maths quiz) of their partners. Although the main goal of their paper is discrimination, one of their findings is that international students exhibit decreasing levels of trust as the number of semesters studied at university increases, which they suggest may reflect cultural adjustment or institutional disadvantages faced specifically by international students. This finding is in line with our results although our measure of exposure to Western education does not rely on tertiary education only. Moreover, since cultural integration is the main focus of our paper, we analyze the impact of exposure to Western education on altruism, preferences for competition, and risk attitudes, in addition to trust and trustworthiness.

Our paper is also related to the papers which investigate the role parents play in shaping the preferences of their children. In this literature, Cipriani et al. (2007) study pro-social values while Dohmen et al. (2011) study risk attitudes and trust. ${ }^{5}$ In contrast, we are interested in the question of how preferences are shaped by the contemporaneous environment. $^{6}$

\footnotetext{
${ }^{5}$ Cipriani et al. (2007) find no evidence for a correlation between parents' and children's behavior. They state that this is consistent with theories from the psychological literature which emphasize the importance of peer effects in the socialization process.

${ }^{6}$ See Fehr and Hoff (2011), who discuss, using examples of the caste system in India and the welfare state in Europe, that preferences can change in response to changes in social institutions and these can potentially have economic consequences.
} 
The structure of the paper is as follows. In the next section, we discuss the experimental design and procedure. In section 3, we present our hypotheses based on results from the literature on behavior in China and the West. After discussing our results in section 4, we report the findings from the post-experimental survey data in section 5 . We conclude in section 6 .

\section{Experimental Design}

To examine behavioral patterns of subjects with different levels of exposure to Western education, we focus on two games that can help elicit social preferences, and two games that measure risk attitudes and preferences for competition. All our subjects hence participated in four games and a survey. In this section, we discuss the subject pool, the experimental design, and the procedure employed in each part of the experiment.

\subsection{Subject Pool}

To facilitate the examination of the pattern and extent of cultural integration, a subject pool of individuals of Chinese ethnicity currently residing in a Western culture (Australia in this case) was selected. Participants varied in their exposure to Australian culture. They ranged in age from 18 to 29 years (with an average of 21). The average participant had spent $33 \%$ of his or her life in Australia. This ranges from having just recently arrived ( $10 \%$ of the sample) to having been born in Australia (another $10 \%$ of the sample). The subject pool included both people with Australian citizenship or permanent residency, and Chinese citizenship. ${ }^{7}$

The experiment was conducted at the University of Melbourne and the participants were recruited through the following means: (i) Students with Chinese names

\footnotetext{
${ }^{7}$ A small number of subjects had New Zealand citizenship or permanent residency.
} 
in the subject database of the Experimental Economics Laboratory at the University of Melbourne were sent emails inviting them to attend the experiment; ${ }^{8}$ (ii) students studying Chinese were sent emails inviting them to participate in the experiment; (iii) the same invitation was placed in the weekly members' newsletter of the Chinese Groups of the University of Melbourne; ${ }^{9}$ (iv) advertisements were placed on the student portal of another university in the city (Monash University) and emails were sent to students studying Intermediate Microeconomics at this university; (v) an open invitation to the experiment was placed on one of the researchers Facebook page and advertisements were also placed on the University of Melbourne and Monash University Facebook pages; (vi) finally, knowledge of the experiment was also spread through word of mouth. In all these cases, subjects were only recruited if they were of Chinese ethnicity.

A total of 120 undergraduate and postgraduate students participated in the experiment. Of these, 48 had Australian citizenship and 72 had Chinese citizenship. The former group consisted of 26 men and 22 women while the latter group consisted of 26 men and 46 women. The participants were studying a wide range of courses, with the largest proportion of students studying economics and business-related courses.

\subsection{Games}

Subjects participated in a Dictator Game, a Trust game, a Risk Game, and a Competition Game. The experiment was conducted using paper and pen, and participants made their decisions on forms. Since we used games that are extensively researched in the experimental literature, we only provide brief descriptions here.

\section{Dictator Game}

\footnotetext{
${ }^{8}$ Students voluntarily sign up to the database in response to standard recruitment drives that occur each semester.

${ }^{9}$ Chinese Groups is the umbrella name applied to the association of five groups: Chinese Culture Society, Chinese Debating Group, Chinese Music Group, Chinese Publishers' Group, and Chinese Theatre Group. There were 400-500 members on their database at the time the invitation was placed.
} 
The Dictator Game captures preferences for fairness. Participants in the game are randomly paired. In each pair, there is an Allocator, referred to as Player 1 in the experiment, and a Recipient, referred to as Player 2. The Allocator is given an endowment of \$40 Australian dollars (AUD) and decides how much of it, in $x$ whole dollars, to keep and how much of it to send to the Recipient. ${ }^{10}$ The Recipient does not make a decision and simply receives the amount sent by the Allocator. The final payoffs for the Allocator and Recipient are $40-x$ and $x$, respectively.

Each participant plays both the Allocator and Recipient roles. Therefore, each participant makes an allocation decision with one anonymous partner and is also the recipient of an allocation from a different anonymous partner. All participant pairings are pre-determined and anonymous, and no two participants are paired twice in the entire experiment to preserve the one-period nature of the game. Participants are informed of these conditions prior to playing the game.

\section{Trust Game}

Participants are paired randomly. In each pair, there is a Sender, referred to as Player A in the experiment, and a Receiver, referred to as Player B. The Sender is given an endowment, \$20 AUD, and has the option of sending some amount, $x(0 \leq x \leq 20)$, to an anonymous Receiver. Any amount sent is tripled by the experimenter before it reaches the Receiver. The Receiver then has the opportunity to send some amount, $y(0 \leq y \leq 3 x)$, back to the Sender. The payoffs are $20-x+y$ to the Sender and $3 x-y$ to the Receiver. The Sender's behavior in this game can be interpreted as an indicator of trust and the Receiver's behavior measures trustworthiness.

\footnotetext{
${ }^{10}$ At the time of the experiment, the exchange rate was approximately 1 Australian dollar $=0.85$ U.S. dollars.
} 
Each participant plays both the Sender and Receiver roles (Burks et. al., 2003; Chaudhuri and Gangadharan, 2007; Bonein and Serra, 2009). ${ }^{11}$ Participants make decisions as Senders and then as Receivers. ${ }^{12}$ As mentioned above, in order to preserve the one-period nature of the game and eliminate reputation-building, no two participants are paired twice during the experiment.

\section{Risk Game}

The Risk Game is similar to the one discussed in Gneezy, Leonard and List (2009). In this game, each participant is given \$20 AUD and the choice to put any amount between 0 and the entire endowment into an 'investment,' which yields triple the amount invested with $50 \%$ probability and 0 with $50 \%$ probability. The outcome is decided at the end of the experiment by the flip of a coin.

\section{Competition Game}

The task used for this game is from Niederle and Vesterlund (2007). It involves summing as many sets of five two-digit numbers as possible in five minutes. An example of a five two-digit sequence is shown to the subjects in the instructions. The numbers are randomly generated and presented in a row with a blank box at the end, where participants write their answers.

\begin{tabular}{|l|l|l|l|l|l|}
\hline 22 & 17 & 83 & 61 & 49 & \\
\hline
\end{tabular}

\footnotetext{
${ }^{11}$ Hall (2009) compares subjects in role-reversal treatments and single-role treatments, and finds no role reversal effects in sending and receiving behavior in the Trust game.

${ }^{12}$ In order to execute the double role design in the Trust Game, two forms were created for each participant (entitled Part A and Part B), one for recording their decision as Sender and one for recording their decision as Receiver. All participants simultaneously recorded their Sender decisions. The forms were then collected and the amounts sent were inserted in an excel file, which generated amounts received for each participant in their role as the Receiver according to a pre-determined pairing. The amounts were recorded manually on the Part B forms, put in an envelope, and returned to the participants. The participants were then instructed to make their Receiver decisions on the Part B forms.
} 
Participants cannot use calculators. Scrap paper is provided for them to use. Before they participate in the task, they have to choose between two different payments schemes: (i) Piece-rate (referred to as Option 1 in the Experiment), which pays $\$ 1$ for each sum correctly completed; or (ii) competitive rate (Option 2), which paid $\$ 2$ for each sum correctly completed if the subject's total number of correct answers is greater than their paired participant, $\$ 0$ if it is less, and $\$ 1$ if there is a tie. Incorrect sums are not paid for, but neither is payment deducted. All participant pairings are pre-determined and anonymous.

Participants are asked two questions before performing the task, which relate to their beliefs about their absolute and relative performance. They are asked how many sums they believe they can successfully complete in five minutes, and what they think their ranking will be among the participants in the room (well above average, above average, average, below average, well below average).

After completing the four games, the participants completed a survey which collected information on their demographic and socio-economic characteristics, the number of years of education completed in Australia, and their attitudes towards trusting behavior.

\subsection{Experimental Procedure}

Participants were seated in a large room and were each given a unique ID number and a set of general instructions for the experiment. ${ }^{13}$ Situating all participants in one room has the advantage of reducing suspicion about pairings or the presence of a co-player, which could lead participants to act more strategically (Frohlich et. al. 2001). The experimenter read aloud all instructions to the participants whilst they read along. We conducted 6

\footnotetext{
${ }^{13}$ The general instructions explained the structure of the experiment and how the payments would be determined. The full set of instructions can be found in the appendix.
} 
sessions and had 16,20 or 24 participants in each session depending on how many subjects showed up for a particular session.

We used a within-subject design where all subjects made decisions in all four games. This allows us to control for individual-specific effects. The games were referred to as 'Task 1,' 'Task 2,' 'Task 3,' and 'Task 4'. Participants were informed that they would play a few tasks, but they were not told specifically how many. We were concerned about order effects, in particular between the social preference games and the Competition game. We wanted to examine whether playing the Competition game before the Dictator and Trust Games induces participants to be less other-regarding. To control for this order effect, the games were played in two different sequences: (i) Dictator, Trust, Risk, Competition; and (ii) Competition, Dictator, Trust, Risk. Participants in sessions 1, 3 and 5 played according to the first sequence while participants in sessions 2,4 and 6 played according to the second sequence. Order effects were however found to be insignificant.

In addition to the general instructions for the experiment, participants were given a set of specific instructions for each game and forms for recording their decisions, which were handed out in envelopes. After the instructions were read out aloud, participants completed the comprehension questions on their forms and recorded their decisions. For each game, once all participants completed their forms, the forms were collected and instructions for the next game were distributed. All forms were distributed and collected in envelopes so as to minimize self-presentation (face-saving) behavior that could be prevalent amongst subjects, particularly of Asian background (Bond and Hwang, 1995). After the last game was completed, the surveys were distributed and completed before the payments were made. 
Participants were informed at the beginning of the experiment that they would be paid $\$ 10$ as a show-up fee and $\$ 5$ for completing the survey in addition to any money they earn during the experiment. They earned between $\$ 15$ and $\$ 75$ in total for the twohour experiment. Participants were also informed that they would be paid for one of the four games played during the experiment. This game was decided at the conclusion of the experiment using a dice. ${ }^{14}$ Only paying for one game, as opposed to paying the average or sum of participants' earnings across the four games, reduces the incentives to use any one game to hedge against the outcome of another. There was no feedback between the games and subjects only received feedback for the game they were paid for. If either the Dictator Game or the Trust Game were picked for payment, a coin was thrown to determine which participants would be paid for their decisions as the Allocator/Sender. The remaining participants were paid for their part as the Recipient/Receiver. ${ }^{15}$ Hence, neither the subjects nor the experimenter knew which game and role would be picked for payment until the end of the session.

\section{Hypotheses}

The participants in our experiment are all university students. Tinto (1988) describes the process of integration to university life as consisting of three stages: Separation, transition, and incorporation. In the separation stage, students disassociate themselves from membership in their past communities. They then go on to acquire, in the transition and incorporation stages, the norms and patterns of behavior appropriate to integration in

\footnotetext{
${ }^{14}$ An 8-sided dice was used. Numbers 1 and 2 corresponded to payment for the first game (Dictator or Competition, depending on the treatment), 3 and 4 to the second game (Trust or Dictator), 5 and 6 to the third game (Risk or Trust), and 7 and 8 to the fourth game (Competition or Risk).

${ }^{15}$ For any toss of the coin, half of the participants were paid for their role as Allocator/Sender, say ID numbers 1-10, while the other half were paid for their role as Recipient/Receiver, say ID numbers 11-20.
} 
their new environment. ${ }^{16}$ In light of Tinto's framework and the large literature in education it motivated, one would expect Chinese students in Australia to display more Western values and patterns of behavior as their exposure to Western education increases. In order to establish whether we are able to discern such cultural integration in the data, we need to know how behavior differs between the Western and Chinese subject pools.

Table 1 compares behavior in China and the West based on results from the literature and experiments we conducted with over 200 participants in China for a separate project (see Cameron et al., 2011). The experiments in China were conducted with a random sample of 26 year olds in Beijing, which is slightly older than most experimental subject pools of university students (for example, the sample used in this paper ranges from 18 to 29 years of age, with a mean of 21). To examine whether we would expect behavior to vary with age, Table 1 also presents data obtained from a cohort of 29 year olds in Beijing. There is no sign of behavior changing markedly with age. ${ }^{17}$ The comparisons are reported for each of the four games that we are interested in.

For the Dictator and Trust games, information about the Western sample is drawn from Chaudhuri and Gangadharan (2007), which uses a sample of Australian students from the University of Melbourne. ${ }^{18}$ The comparison of behavior in the Beijing sample with the Melbourne sample reveals a number of things. First, Western subjects send

\footnotetext{
${ }^{16}$ Tinto's conceptual framework is based on the work of Van Gennep, a Dutch anthropologist. Van Gennep's work focuses on the movement of individuals in tribal societies from membership in one group to membership in another. In previous work, Tinto (1975) argues that integration to university life consists of both social and academic integration. He stresses the role played by relationships with peers in social integration.

${ }^{17}$ The only exception is the Risk game where the younger cohort took less risk. This suggests that our finding below is an underestimate of the cultural differences since we would expect to find an even greater difference between the risk preferences of the Western and Chinese subject pools if they were the same age. Another concern one may have is that the Melbourne sample is composed of university students. In contrast, only $67 \%$ of the Beijing sample are university-educated (although $99 \%$ of that sample have at least a 3-year college education). Restricting the sample to university graduates does not change the conclusions drawn from the comparisons.

${ }^{18}$ Note that Chaudhuri and Gangadharan (2007) also use role-reversal games, similar to the ones used in this paper.
} 
substantially less in the Dictator game than Chinese subjects (13\% in Australia versus $40 \%$ in China). Similar differences are observed in the Trust game also, for the Receivers' behavior. The Chinese sample return 30\% while the Australian sample return $18 \%$. The difference in the Senders' behavior in the Trust game is more muted $-43 \%$ is sent in the Australian subject pool versus $46 \%$ in the Beijing sample. ${ }^{19}$

Sending in the Trust game involves risk-taking, so differences in risk-taking may be obscuring differences in other-regarding preferences. Table 1 shows that Western subjects invest substantially more in the risky option than Chinese subjects. ${ }^{20}$ On average Western subjects invest $68 \%$ of their endowment in the risky option, compared to $58 \%$ for Chinese subjects. Table 1 also shows that Western subjects are more likely than Chinese subjects to choose the competitive option over the piece rate option in the Competition game $(51 \%$ vs. $44 \%))^{21}$ Note that since choosing the competitive option involves risk-taking, differences in risk attitudes may also be behind this result.

Broadly speaking, each of these differences is in line with generalizations about differences between Western culture and traditional Chinese culture. China is a Communist state, with recently embraced markets operating in conjunction with large state-owned enterprises. Chinese society is heavily influenced by Confucian and Buddhist

\footnotetext{
${ }^{19}$ Qingsong and Dayong (2010) also compare Chinese subjects with U.S. subjects and find that Chinese subjects are more trusting and more trust-worthy than U.S. subjects.

${ }^{20}$ The comparison here is with Haigh and List (2005), which uses a sample of undergraduates at the University of Maryland. This is an underestimate of how risk-taking the U.S. students are as the gamble they faced was more risky (66\% chance of getting 0 and $33 \%$ chance of getting a $250 \%$ return) than that played by the Chinese sample. We report the "infrequent feedback" result from Haigh and List (2005) here as it is closest to our one-shot game.

${ }^{21}$ The Western sample data is from Niederle and Vesterlund (2005). Respondents were University of Pittsburgh students. The reported figure is the weighted average of male and female behaviour, weighted to reflect the proportions in our sample.
} 
collectivist philosophy. In contrast, Western society is influenced by capitalist and individualist philosophy. ${ }^{22}$

These cultural comparisons lead us to posit the following hypotheses.

Hypothesis 1: Greater exposure to Western education leads to a decrease in altruism.

Hypothesis 2: Greater exposure to Western education leads to a decrease in trust.

Hypothesis 3: Greater exposure to Western education leads to a decrease in trustworthiness.

Hypothesis 4: Greater exposure to Western education leads to an increase in risk-taking behavior.

Hypothesis 5: Greater exposure to Western education leads to an increase in competitiveness.

\section{$4 \quad$ Results}

We start with a comparison of means of behavior. ${ }^{23}$ Tables A1 and A2 present summary statistics of our data. The mean Western education share in our sample is $45 \%$. In terms of identifying oneself as Australian, $25.8 \%$ of participants strongly identify as Australian and $27.5 \%$ identify as Australian. Table 2 presents means of behavior broken down by whether individuals received more or less than $50 \%$ of their education in Australia. This variable is strongly correlated with how strongly people identify themselves as being Australian $(\rho=0.80)$ and also the percentage of the person's lifetime that has been spent in Australia $(\rho=0.90) .{ }^{24}$ It however is a stronger determinant of behavior in the experiments

\footnotetext{
${ }^{22}$ Collectivists tend to focus on others, whilst individualists tend to focus on the self (Schultz, Unipan, and Gamba, 2000). Tata and Leong (1994) report that Chinese Americans who are more acculturated exhibit higher levels of individualism.

${ }^{23}$ As discussed in section 2.3, the subjects participated in the games in two different sequences. Since we find that behaviour does not depend on the order in which the games were played, we pool the data from the two sequences.

${ }^{24}$ Participants were categorised as identifying as being Australian if they reported that they "agree" or "strongly agree" with the following statement: "In many ways I think of myself as Australian."
} 
than either of these two alternative variables, suggesting that education has an impact on preferences beyond merely spending time in a country. This is not surprising since immigrants get more direct exposure to the cultural traits of the host country through education. Education also provides an opportunity to actively engage with the citizens of the host country.

Since the categorization of education share into more or less than $50 \%$ is somewhat arbitrary, Table 2 is supplemented with Figure 1, which presents nonparametric regressions of indicators of behavior in the games on the share of the participant's education that was gained in Australia. Figure 1 shows every data point. Both Table 2 and Figure 1a show that receiving more of one's education in Australia is associated with giving less in the Dictator Game, although the difference in the means reported in Table 2 is not statistically significant. Those with more than $50 \%$ of their education attained in Australia gave an average of $25.8 \%$ of the endowment, compared with $31.8 \%$ for those who received less than $50 \%$ of their education. We will further explore the impact of Western education share on behavior in the Dictator game, controlling for other covariates, in the regressions below.

The amount sent and returned in the Trust game differs in the same way. Those with a greater share of Western education send significantly less (26.0\% versus $37.8 \%$, $\mathrm{p}<0.01$ ). The relationship is also apparent in Figure $1 \mathrm{~b}$. The differences in the amounts returned are in the same direction, but are not statistically significant.

In the Risk game, the differences in the amounts invested in the risky option is consistent with our original hypotheses. That is, the more exposure a subject has to Western education, the greater the risk-taking behavior, although the differences are insignificant. 
Finally, the percentage of participants who choose the competitive payment scheme in the Competition game is lower amongst those who received more than $50 \%$ of their education in the West. The differences in means are relatively small though $(35.6 \%$ versus $38.3 \%$ ). Figure $1 \mathrm{e}$ is illustrative. It shows a relatively strong inverted Urelationship between willingness to compete and share of Western education. The willingness to compete increases from around $10 \%$ for those with very little Western education (less than one tenth of their total education) up to about $46 \%$ for those with a $40 \%$ Western education share. It then drops to about $30 \%$ for those who are $100 \%$ Western educated.

To summarize, Table 2 shows the direction of change with greater exposure to Western education to be as hypothesized for all of the games, except for the Competition game. The relationship is statistically significant only in the case of the Trust game (for the Sender). We now turn to regression models that include several controls for determinants of behavior and use a continuous variable to examine the share of Western education.

Table 3 reports the results of regression analysis of the behavior in each of the games. All specifications control for the age, gender, and religion of the individual. ${ }^{25} \mathrm{We}$ also control for whether the individual is an economics major as this has been shown to be a strong determinant of behavior in previous research. Finally, we control for the years of work force experience as exposure to the "real world" may affect behavior by influencing the cultural integration process. Some specifications include additional controls which will be discussed below. The main variable of interest in the regressions is Western education share, which captures the extent of exposure to Western culture. Some

\footnotetext{
${ }^{25}$ Note that age is not significant in any of the specifications which adds further weight to our argument above that behavior in the Beijing sample can be compared with the behavior in the Western student samples. Note also that dropping age from the regressions does not affect the results.
} 
specifications include its square. ${ }^{26}$ Unless otherwise noted we report coefficients from tobit estimations for continuous variables censored at 0 and 100. Marginal effects from probit estimation are reported for dichotomous dependent variables. Ordered probits are estimated for categorical variables.

Column (1) shows that Western education is strongly negatively associated with the amount given in the Dictator game. Each additional 10\% of education that is received in Australia is associated with a 1.87 percentage point decrease in the amount given. Hence, an individual who received all of his or her education in China gives on average approximately $19 \%$ more of the endowment than an individual who received all of his or her education in Australia. The only other variables that are significant in the regression are the variables indicating whether the individual is male and year of work experience. Consistent with findings in the literature, men on average give $17 \%$ less of the endowment away. An extra year of work experience is associated with sending 3\% more of the endowment. This may be an income effect.

Column (2) shows the results for sending in the Trust game. Western education share is again statistically significant. A $10 \%$ increase in Western education share is associated with giving 3.5\% less of the endowment. Column (3) examines this result more closely. It includes controls for the amount sent in the Dictator game and the amount invested in the Risk game. It thus decomposes the total effect. The results show that the more that is sent in the Dictator game, the more that is sent in the Trust game. Similarly, the more risk one takes in the Risk game (and hence the more risk-loving one is), the more risk that is taken - in terms of sending more - in the Trust game, although this is not statistically significant $(\mathrm{p}=0.13)$. Western education share remains significant

\footnotetext{
${ }^{26}$ We estimated a quadratic relationship with Western education share for all the games, but it was only statistically significant in the Competition game.
} 
once we control for altruism and risk-aversion. Hence, it appears that having a Western education makes one less trusting per se, even after controlling for the effects of altruism and risk-aversion.

Column (4) examines the returning behavior in the Trust game. Similarly, Western education is negatively related to the amount sent. The coefficient is significant at the $10 \%$ level $(p=0.055)$. A $10 \%$ increase in the share of education received in the West corresponds to an average decrease in the amount of the endowment returned by $2.5 \%$. Players reciprocate in the sense that the more that is given to them, the more they return. Every extra percent of the endowment sent is on average reciprocated with an extra $0.7 \%$ being sent back. ${ }^{27}$ This decision is similar in nature to the decision in the Dictator game, and Column (5) shows that Dictator game behavior is a significant predictor of reciprocity in the Trust game. ${ }^{28}$ Once altruism is controlled for, Western education share is no longer significant which suggests that differences in altruism, rather than reciprocity per se, are driving this result.

Column (6) shows the results for the Risk game. The point estimate on Western education share is positive but insignificant. Being male and majoring in economics are both associated with taking significantly more risk. The effect of Western education share however differs by gender. Figure 2 presents the data separately by gender for each game. In most of the games, the same pattern is evident for men and women. It is only in the Risk game and to a lesser extent in the Competition game where the genders differ. Figure $2 \mathrm{~d}$ shows that women become more risk-loving, the more education they receive in the West. In contrast, men's behavior does not change markedly. Columns (7) and (8)

\footnotetext{
${ }^{27}$ A $1 \%$ increase in the amount sent is a $\$ 0.20$ increase. Player B then receives three times this amount which is $\$ 0.60$. 0.6 times the coefficient on the amount received $(0.16)$ is 0.696 .

${ }^{28}$ This finding is consistent with those in Holm and Danielson (2005), and Chaudhuri and Gangadharan (2007).
} 
in Table 3 present results separately for men and women in the Risk game. Again no relationship is found for men. For women, Western education share is positively and significantly related to taking more risk. A female participant with no exposure to Western education on average invests $24 \%$ less of the endowment in the risky option than a female participant who has received her entire education in the West. It is not clear why men's behavior does not evolve towards that of the host country with regard to risktaking. ${ }^{29}$ The change in women's behavior implies that amongst our respondents who have received most of their education in the West, there is very little gender difference. This is puzzling as in the West, it is well-established that men take more risk than women. $^{30}$

Column (9) presents the results for the Competition game. We estimate probits of the decision of whether to compete or not, and report marginal effects. The results show a statistically significant inverted-U shape with the maximum participation in competition taking place among those who received $47 \%$ of their education in the West. ${ }^{31}$ Men were $17.3 \%$ more likely to compete than women (significant at the $10 \%$ level). Although confidence in one's ability to complete the task is a factor in the decision to participate in the competition, Western education share continues to be significant (at the $10 \%$ level) once we control for individuals' expectations about their performance, as shown in Column (10). Including differences in risk attitudes also does not explain away the relationship, as seen in Column (11).

\footnotetext{
${ }^{29}$ A possible explanation is that women are more likely to respond to social and environmental cues than men (Croson and Gneezy 2009). Women may thus respond more strongly to the higher risk-taking they observe in Australia than men.

${ }^{30}$ Croson and Gneezy (2009) point out in their recent review of gender differences in preferences that "most lab and field studies indicate that women are more risk-averse than men" (p. 467). Booth and Nolen (forthcoming) find that the gender difference in risk-taking is socio-culturally determined. Girls at coeducational schools in the U.K. take less risk than boys, but girls in a single-sex educational environment take just as much risk as boys.

${ }^{31}$ This number is the maximum of the quadratic estimated in column (9).
} 
The results for the Competition game also exhibit gender differences, as can be seen from Figure 2e. The figure shows that moderate exposure to the West is associated with increases in competitive behavior for both men and women. However, for women, additional exposure (beyond $50 \%$ of education) is associated with a decline in competitiveness.

Table 4 presents the regression results for the Competition game separately by gender and shows that the coefficient on Western education share is being driven by women. A comparison of columns (1) and (4) in Table 4 reveals that there is no relationship between Western education share and competitiveness for men. However, there is for women and it is an inverted- $U$ relationship as described above. The extent of competitiveness is being driven by their beliefs in their abilities which, as Column (8) shows, also have an inverted-U shape with Western education share. Figure 3 presents a non-parametric regression of individuals' beliefs in their maths abilities by gender. ${ }^{32}$ It is relatively flat for men. For women, it has a strong inverted-U shape. Confidence may increase initially as immigrants realize they are better skilled than locals in mathematics. However, receiving more than about one third of one's education in Australia is associated with a decline in one's belief about one's maths ability for women.

One question is whether the change in women's confidence levels is accompanied by a similar change in their performance levels. The number of sums completed correctly decreases with Western education share for women. Men's performance also decreases with greater Western education share, although not to the same extent. However, their confidence does not.

\footnotetext{
${ }^{32}$ In the figure, we use the following coding: $5=$ well above average, $4=$ above average, $3=$ average, $2=$ below average, and $1=$ well below average.
} 
For participants with very little Western education (less than $5 \%$ ), there is no gender gap in the number of sums completed correctly. If anything, women with very little Western education in our sample perform slightly better than their male counterparts. It is only with Western education that the gender gap opens up. ${ }^{33}$ Mathematical achievement has been found to be strongly determined by socio-cultural factors (Hyde and Mertz, 2009). Women's mathematical ability in Australia may suffer as a result of a loss of confidence induced by their cultural surrounds. Australian girls on average perform at lower levels than Australian boys in standardized maths tests. ${ }^{34}$

\subsection{Selection Effects}

A possible concern with our results is that they may be driven by selection effects. Selection is a key element in the migration literature as migrants are thought to be fundamentally different from non-migrants. To some extent, we avoid this problem in this paper as our entire sample consists of Chinese immigrants. However, one could argue that within our sample there are two distinct groups - individuals whose family migrated to Australia permanently, and foreign students who have migrated (possibly temporarily) to gain an education. It is possible that fundamental differences between these two groups are driving our results as the "type of migrant" is correlated with length of stay in Australia and hence Western education share. To examine this issue, we divided our sample into those who emigrated before the age of 16 , as these people would have come as part of a family unit, and those who came to Australia at age 16 or older. Of those who came before age 16 , the mean share of education obtained in Australia is $84 \%$. Of the group that came at an older age, the mean share of education obtained in Australia is $21 \%$. Table 5 presents the coefficients on the education share variables for these two

\footnotetext{
${ }^{33}$ Women completed an average of 13.3 sums correctly across our entire sample and men completed an average of 14.9 sums correctly.

${ }^{34}$ See "Numbers point to maths 'gap"” in The Age, May 2, 2011.
} 
groups separately. It also presents tests of equality of coefficients across the two groups. The statistical significance of the coefficient estimates is reduced because of the smaller sample sizes. However, the point estimates in the two sets of regressions are always of the same sign and of similar magnitude. ${ }^{35}$ Tests of equality of the coefficients cannot reject the finding that the coefficients are insignificantly different from one another. Hence, it seems that the same process is at work in both sub-samples. We conclude that it is unlikely that our results are being driven by fundamental differences in behavior between the two groups.

\section{Experimental Data versus Survey Data}

Our post-experiment survey included two hypothetical measures of trust. In particular, we asked the participants the following questions: (i) Generally speaking, would you say that most people can be trusted, or that you need to be very careful in dealing with people? and (ii) Would you say that most of the time people try to be helpful, or that they are mostly just looking out for themselves? In this section, we examine to what extent we can discern a change in behavioral values using these survey-based measures.

Table 6 presents correlations between these measures and the experimental behavior. None of the correlations are particularly high (all below 0.25), but believing that people try to be helpful is associated with sending more in the Dictator game and sending more back in the Trust game (although not sending more as Player 1 in the Trust game). Believing most people can be trusted is associated with sending more in the Trust game (as Player 1).

Table 7 reports regression results similar to Table 2 with the survey-based measures as the dependent variables. We report marginal effects from probit estimation.

\footnotetext{
${ }^{35}$ One exception is the coefficients on the square term in the Competition game regression where both coefficients are small and insignificant, but one is positive and one is negative.
} 
As can be seen from the table, Western education share is an insignificant determinant of both survey-based measures of trust.

These results show that survey-based measures of trust, although positively correlated with behavior in the Trust game, are unable to detect changes in immigrants' preferences. This may be because they provide only a noisy measure of trust and/or may not accurately elicit information. It may also be the case that the predictive power of survey-based measures of trust depends on the culture (Holm and Danielson, 2005). ${ }^{36}$ Experimental data is incentivized by the use of salient monetary awards and have been shown to be a significant predictor of real world behavior. ${ }^{37}$ Experimental data is thus likely to be a more reliable predictor of people's actual behavioral preferences and have in this instance been able to reveal changes in immigrants' preferences that survey data could not.

\section{Conclusion}

We have investigated the cultural integration patterns of individuals of Chinese ethnicity in Australia. Our results reveal that exposure to Western education has a significant impact on social preferences, preferences for competition, and risk attitudes. Specifically, it has a strong negative impact on altruism, trust, and trustworthiness. While it increases the risk-taking behavior of women, it has no impact on the risk attitudes of men. Finally, for women, greater exposure to Western education reduces their willingness to participate in competitive tasks. This seems to be driven by a decline in their confidence in their ability to perform and may be particular to the task employed here which draws on simple mathematical ability. There is no impact on the competitiveness of men.

\footnotetext{
${ }^{36}$ Holm and Danielson (2005) find a plausible relation between survey trust and trust behavior in experiments in Sweden but not in Tanzania.

${ }^{37}$ See, for example, Leibbrandt, Gneezy and List (2009) and Liu (forthcoming).
} 
Our results have implications for the policy debate surrounding cultural diversity and immigration. An important question that policy makers face is whether it is better to promote cultural integration or diversity. Education is a potential policy instrument in this respect. Our results reveal that education does indeed play an important role in cultural integration. Australian immigration and education policy does not actively seek to assimilate immigrants. Rather, it aims to promote multiculturalism. ${ }^{38}$ Our results suggest that immigrants' behavior evolves towards that of the host country naturally as a result of engaging with the institutions of the host country, in this case the education system.

Cultural integration may of course vary across destinations and groups. In future research, it would be useful to determine to what extent our results generalize to other destinations and groups.

\footnotetext{
${ }^{38}$ See http://www.immi.gov.au/media/publications/settle/_pdf/chap01web.pdf.
} 


\section{References}

Alesina, A., Y. Algan, P. Cahuc, and P. Giuliano. 2010. "Family Values and the Regulation of Labor," NBER Working Paper No. 15747.

Alesina, A. and N. Fuchs-Schuendeln. 2007. "Good Bye Lenin (or not?) The Effect of Communism on People's Preferences," American Economic Review, 97, 15071528.

Alesina, A. and P. Giuliano. 2011. "Preferences for Redistribution," in Handbook of Social Economics, J. Benhabib, A. Bisin, and M. O. Jackson (eds), Vol. 1A, The Netherlands: North Holland.

Alesina, A. and P. Giuliano. 2011. "Family Ties and Political Participation," Journal of the European Economic Association, 9(5), 817-839.

Algan, Y. and P. Cahuc. 2009. "Civic Virtue and Labor Market Institutions," American Economic Journal: Macroeconomics, 1(1): 111-145.

Algan, Y. and P. Cahuc. 2010. "Inherited Trust and Growth," American Economic Review, 100, 2060-2092.

Bisin, A. E. Patacchini, T. Verdier, and Y. Zenou. 2008. "Are Muslim Immigrants Different in Terms of Cultural Integration?" Journal of the European Economic Association, 6(2-3), 445-456.

Bond, M. H. and K. Hwang. 1995. "The Social Psychology of the Chinese People," in M. H. Bond (Ed.), The Psychology of the Chinese People, Oxford University Press, Hong Kong, pp. 213-66.

Bonein, A. and D. Serra. 2009. "Gender Pairing Bias in Trustworthiness," Journal of Socio-Economics, 38, 779-89.

Booth, A. and P. Nolen. Forthcoming. "Gender Differences in Risk Behaviour: Does Nurture Matter?" Economic Journal.

Buchan, N. R., E. J. Johnson and R. T. A. Croson. 2006. "Let's Get Personal: An International Examination of the Influence of Communication, Culture and Social Distance on Other Regarding Preferences," Journal of Economic Behavior \& Organization, 60(3), 373-98.

Burks, S. V., J. P. Carpenter, and E. Verhoogen. 2003. "Playing Both Roles in the Trust Game," Journal of Economic Behavior \& Organization, 51(2), 195-216.

Chaudhuri, A. and L. Gangadharan. 2007. "An Experimental Analysis of Trust and Trustworthiness," Southern Economic Journal, 73(4), 959-85.

Chen, Y., S. Li., T. X. Liu and M. Shih. 2010. "Which Hat to Wear? Impact of Natural Identities on Coordination and Cooperation," University of Michigan, mimeo.

Cipriani, M., P. Giuliano, and O. Jeanne. 2007. "Like Mother Like Son? Experimental Evidence on the Transmission of Values from Parents to Children," IZA Discussion Paper No. 2768.

Constant, A. F. and K. F. Zimmermann. 2008. "Measuring Ethnic Identity and its Impact on Economic Outcomes," Journal of the European Economic Association, 6(2-3), 424-433.

Croson, R. and U. Gneezy. 2009. "Gender Differences in Preferences," Journal of Economic Literature, 2009, 47(2), 448-474.

De Palo, D., R. Faini, and A. Venturini. 2006. "The Social Assimilation of Immigrants," IZA Discussion Paper No. 2439.

Dohmen, T., A. Falk, D. Huffman, and U. Sunde. Forthcoming. "Intergenerational Transmission of Risk and Trust Attitudes," Review of Economic Studies. 
Fehr, E. and K. Hoff. 2011. "Tastes, Castes and Culture: The Influence of Society on Preferences," World Bank Policy Research Working Paper No. 5760.

Fernandez, R. and A. Fogli. 2009. "Culture: An Empirical Investigation of Beliefs, Work, and Fertility," American Economic Journal: Macroeconomics, 1(1), 146-77.

Frohlich, N., J. Oppenheimer, and J. B. Moore. 2001. "Some Doubts about Measuring Self-Interest Using Dictator Experiments: The Costs of Anonymity," Journal of Economic Behavior \& Organization, 46, 271-90.

Gneezy, U, K. L. Leonard, and J. A. List. 2009. "Gender Differences in Competition: Evidence from a Matrilineal and a Patriarchal Society," Econometrica, 77(5), 163764.

Giuliano, P. 2007. "Living Arrangements in Western Europe: Does Cultural Origin Matter?" Journal of the European Economic Association, 5(5), 927-952.

Guiso, L., P. Sapienza, and L. Zingales. 2006. "Does Culture Affect Economic Outcomes?" Journal of Economic Perspectives, 20(2), 23-48.

Haigh, M. and J. A. List. 2005. "Do Professional Traders Exhibit Myopic Loss Aversion? An Experimental Analysis," Journal of Finance, 60 (1), 523-534.

Hall, D. 2009. "Using Role-Reversal in Laboratory Experiments," Georgia State University, mimeo.

Henrich, J., R. Boyd, S. Bowles, C. Camerer, E. Fehr, H. Gintis, R. McElreath, M. Alvard, A. Barr, J. Ensminger, N. Smith-Henrich, K. Hill, F. Gil-White, M. Gurvan, F. Marlowe, J. Patton, and D. Tracer. 2005. "'Economic Man' in CrossCultural Perspective: Behavioral Experiments in 15 Small-Scale Societies," Behavioral and Brain and Sciences, 28, 795-815.

Holm, H. J. and A. Danielson. 2005. "Tropic Trust Versus Nordic Trust: Experimental Evidence From Tanzania And Sweden," Economic Journal, 115(503), 505-32.

Hyde, J. and J. Mertz. 2009. "Gender, Culture, and Mathematics Performance," Proceedings of the National Academy of Science of the U.S.A., 106(22), 8801-7.

Guillen P., and Ji, D. 2011. "Trust, Discrimination and Acculturation: Experimental Evidence on International and Domestic University Students in Australia', Journal of Socio-Economics, 40, 594-608.

Leibbrandt, A., Gneezy, U. and J. A. List. 2009. "Ode to the Sea: The Socio-Ecological Underpinnings of Social Norms," University of Chicago, mimeo.

Liu, E. Forthcoming. "Time to Change What to Sow: Risk Preferences and Technology Adoption Decisions of Cotton Farmers in China," Review of Economics and Statistics.

Luttmer, E. F. P. and M. Singhal. 2011. "Culture, Context, and the Taste for Redistribution," American Economic Journal: Economic Policy, 3(1): 157-79.

Manning, A. and S. Roy. 2010. "Culture Clash or Culture Club? National Identity in Britain," Economic Journal Features, 120, F72-F100.

Niederle, M. and L. Vesterlund. 2007. "Do Women Shy Away from Competition? Do Men Compete Too Much?” Quarterly Journal of Economics, 122(3), 1067-101.

Qingsong, R. and L. Dayong. 2010. "Comparative Analysis of Trust Games between China and America: Experimental Research," International Conference on Ebusiness and E-government.

Schultz, P. W., J. B. Unipan, and R. J. Gamba. 2000. "Acculturation and Ecological Worldview among Latino Americans," Journal of Environmental Education, 31, 22-8. 
Tata, S. P. and F. T. L. Leong. 1994. 'Individualism - Collectivism, Social-network Orientation, and Acculturation as Professional Psychological Help among Chinese Americans," Journal of Counselling Psychology, 41, 280-7.

Tinto, V. 1975. "Dropout from Higher Education: A Theoretical Synthesis of Recent Research," Review of Educational Research, 45(1), 89-125.

Tinto, V. 1988. "Stages of Student Departure: Reflections on the Longitudinal Character of Student Leaving," Journal of Higher Education, 59(4), 438-455. 
Figure 1: Non-Parametric Regressions

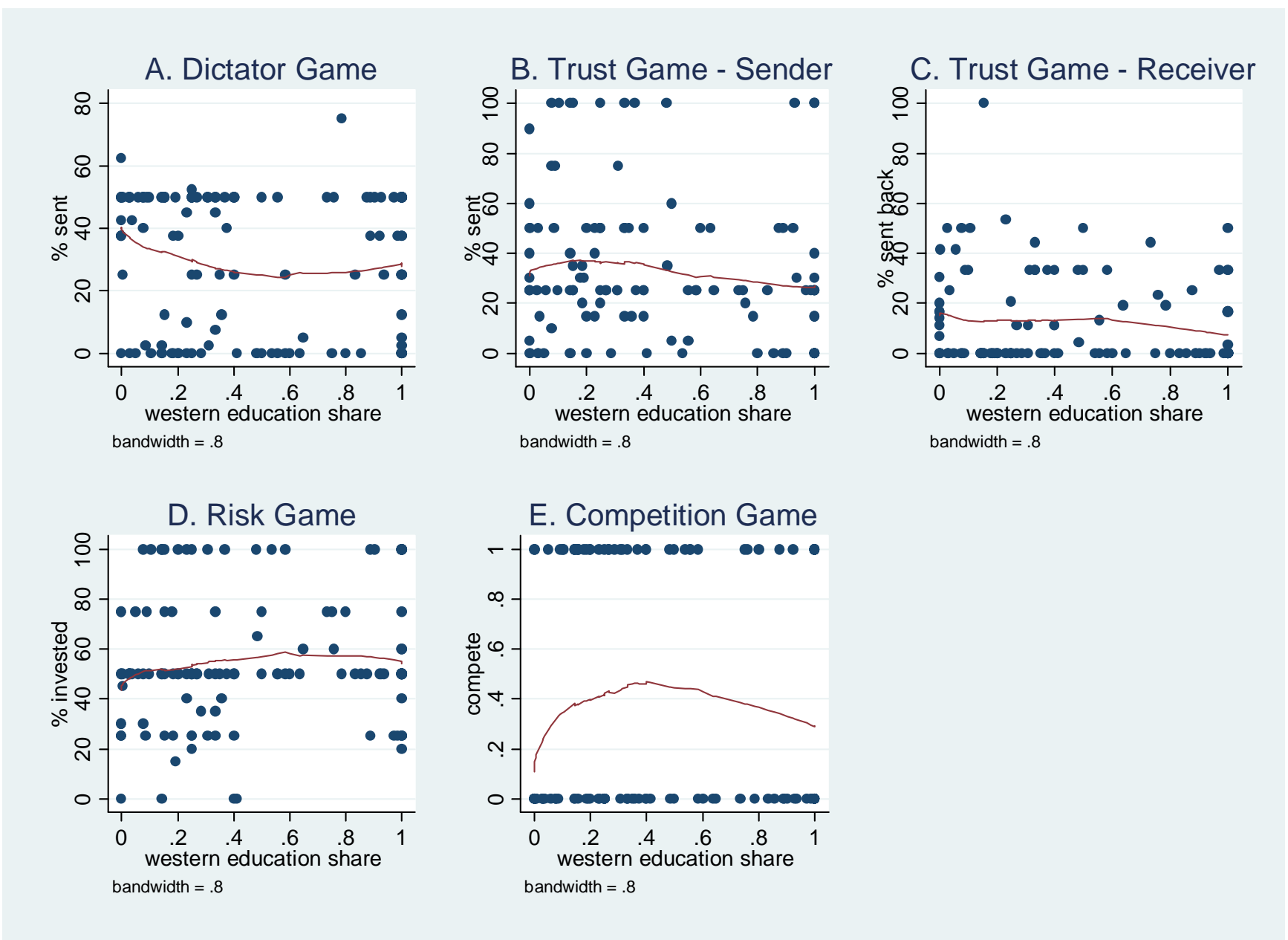


Figure 2: Nonparametric Regressions by Gender
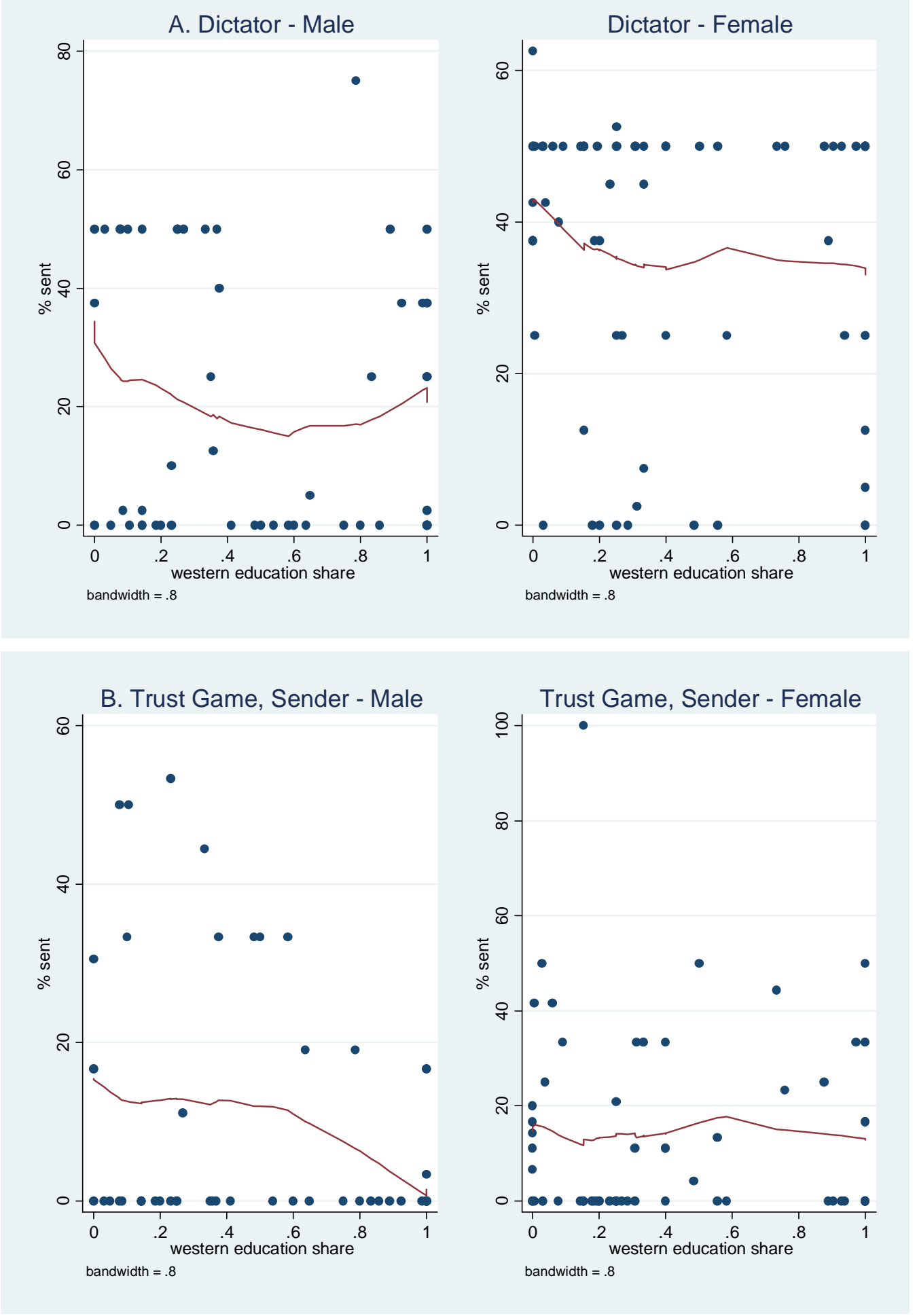

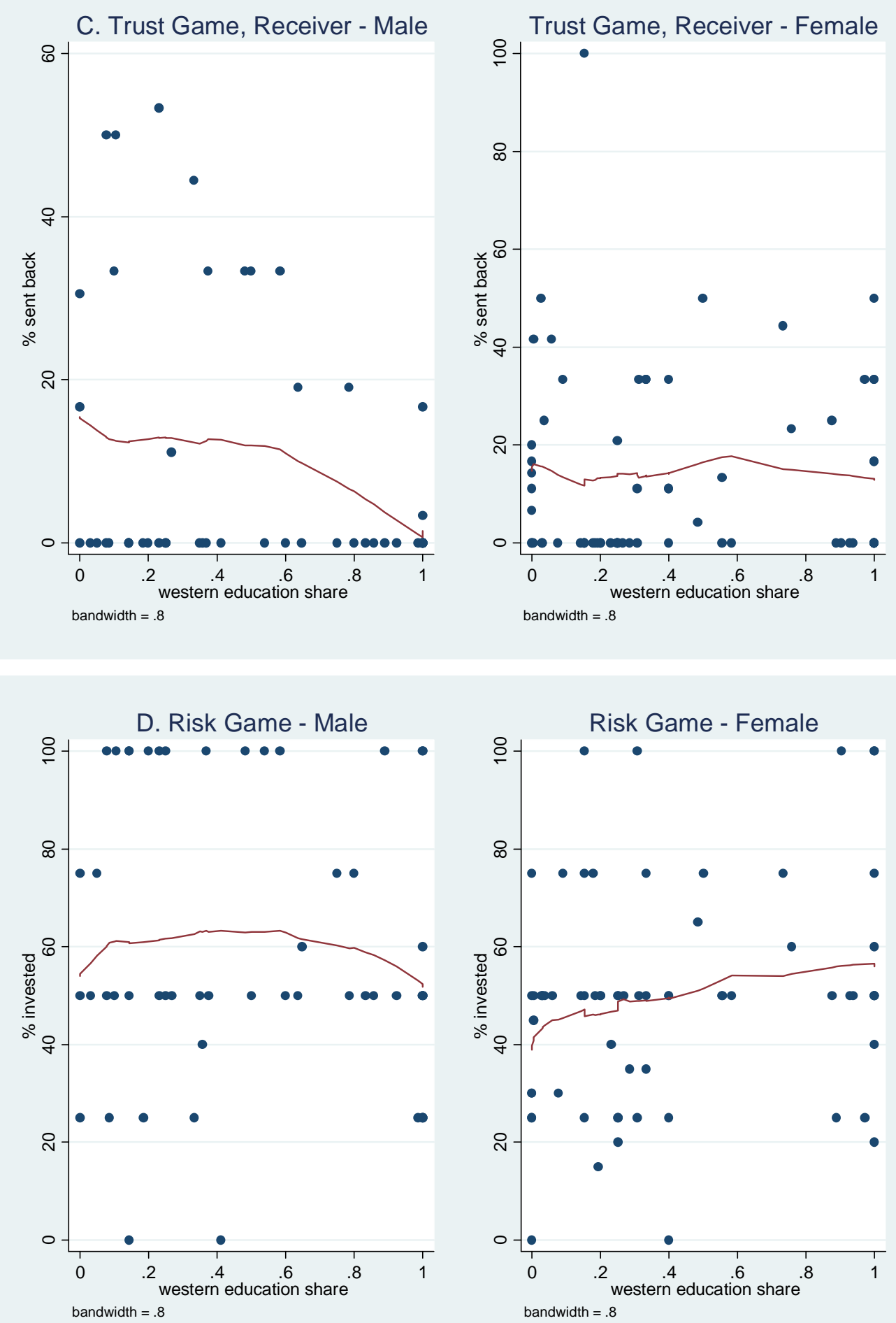
E. Competition Game - Male

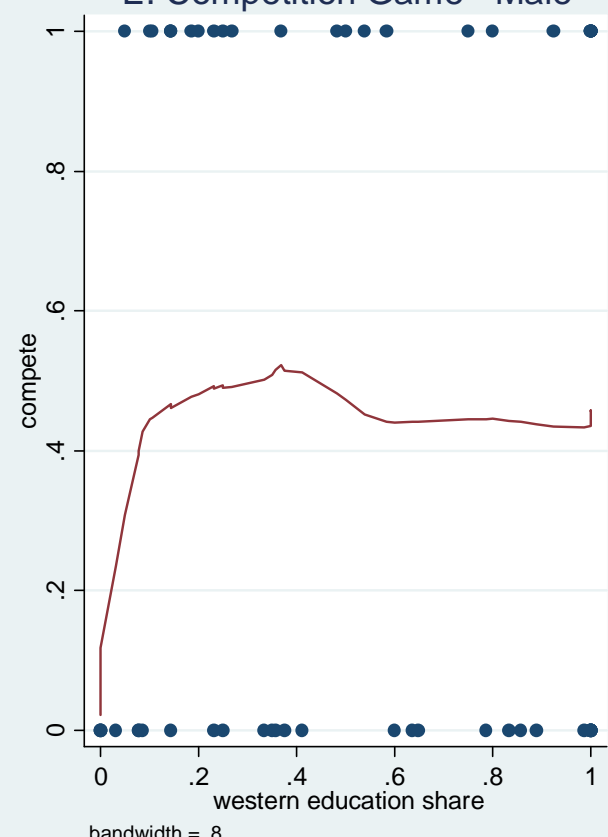

Competition Game - Female

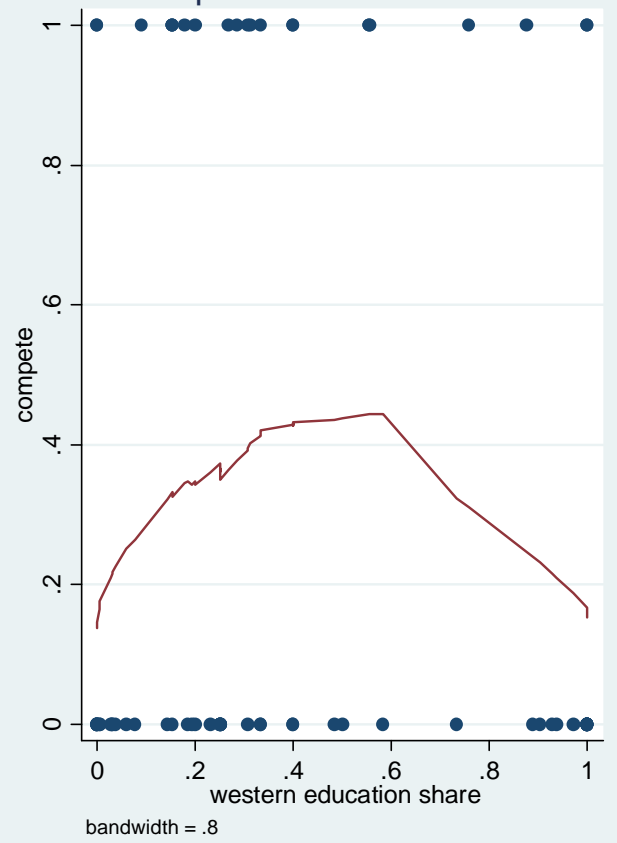


Figure 3: Beliefs and Performance in the Competition Game by Gender
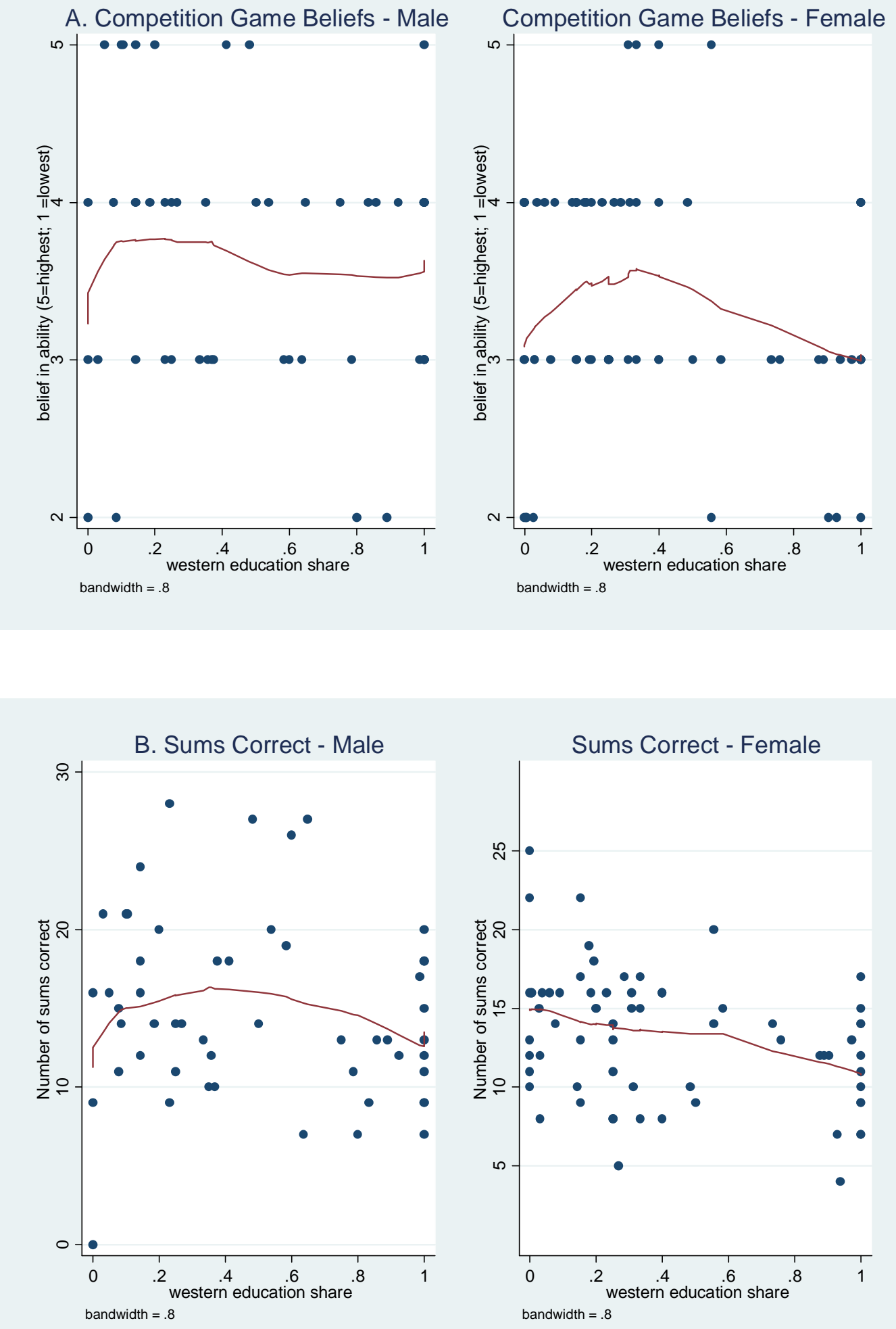
Table 1: China - West Comparisons

\begin{tabular}{l|c|c|c}
\hline & Australia/US & $\begin{array}{c}\text { China } \\
\text { (26 year olds) }\end{array}$ & $\begin{array}{c}\text { China } \\
\text { (29 year olds) }\end{array}$ \\
\hline $\begin{array}{l}\text { \% sent in Dictator game } \\
\text { \% sent in Trust game }\end{array}$ & $13.0^{\mathrm{a}}$ & 40.9 & 39.0 \\
\% returned in Trust & $18.0^{\mathrm{a}}$ & 46.3 & 45.3 \\
game & 29.4 & 32.0 \\
\% invested in Risk game & $68.0^{\mathrm{b}}$ & 55.5 & 60.6 \\
\% choosing to compete & $51.3^{\mathrm{c}}$ & 42.6 & 45.4 \\
\hline
\end{tabular}

${ }^{a}$ From Chaudhuri and Gangadharan (2007) conducted with students at the University of Melbourne, Australia.

${ }^{\mathrm{b}}$ From Haigh and List (2006). Participants were undergraduates at the University of Maryland.

${ }^{\mathrm{c}}$ From Niederle and Vesterlund (2005). Respondents were students at the University of Pittsburgh.

Table 2: Summary Statistics by Western Education Share

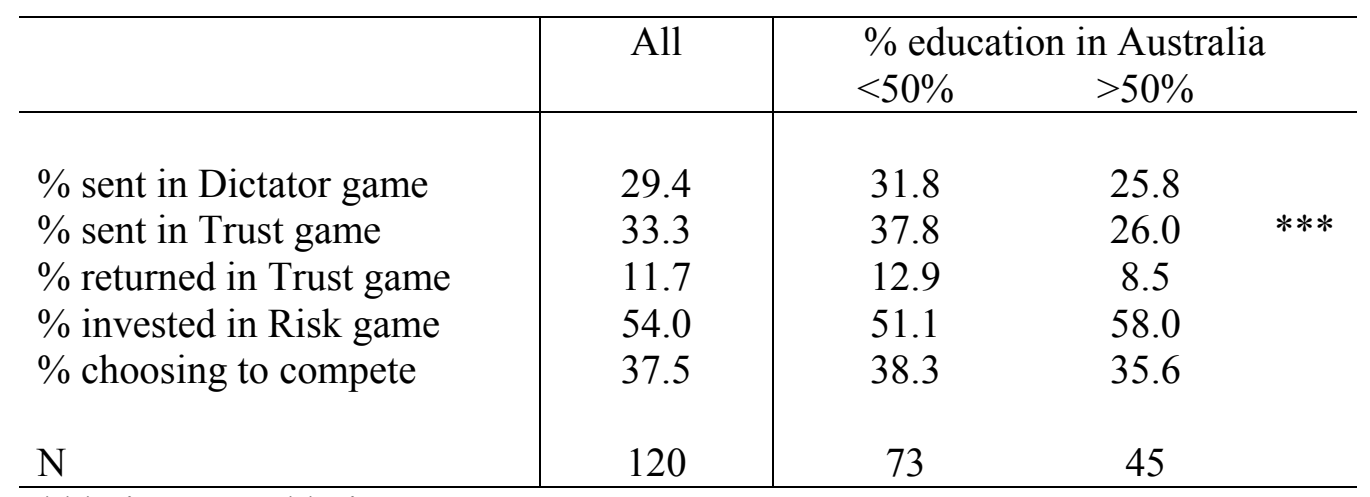

$* * * \operatorname{sig}$ at $1 \% ; * * \operatorname{sig}$ at $5 \%$. 
Table 3 - Regression Results using Western Education Share

\begin{tabular}{|c|c|c|c|c|c|c|c|c|c|c|c|}
\hline & (1) & (2) & (3) & (4) & (5) & (6) & (7) & (8) & (9) & (10) & (11) \\
\hline & $\begin{array}{c}\text { Dictator } \\
\% \text { sent }\end{array}$ & $\begin{array}{c}\text { Trust } \\
\% \text { sent }\end{array}$ & $\begin{array}{c}\text { Trust } \\
\% \text { sent }\end{array}$ & $\begin{array}{c}\text { Trust } \\
\% \text { return }\end{array}$ & $\begin{array}{c}\text { Trust } \\
\% \text { return }\end{array}$ & $\begin{array}{c}\text { Risk } \\
\% \text { invest }\end{array}$ & $\begin{array}{c}\text { Risk } \\
\% \text { invest } \\
\text { Men }\end{array}$ & $\begin{array}{c}\text { Risk } \\
\% \text { invest } \\
\text { Women }\end{array}$ & Compete & Compete & Compete \\
\hline Western educ sh & $\begin{array}{c}-18.72 * * \\
{[9.159]}\end{array}$ & $\begin{array}{c}-35.48^{* *} \\
{[14.19]}\end{array}$ & $\begin{array}{c}-28.39 * * \\
{[1394]}\end{array}$ & $\begin{array}{l}-24.72 * \\
{[1273]}\end{array}$ & $\begin{array}{l}-18.10 \\
\end{array}$ & $\begin{array}{c}9.084 \\
{[10081}\end{array}$ & $\begin{array}{l}-22.82 \\
{[21}\end{array}$ & $\begin{array}{l}24.02 * * \\
\end{array}$ & $1.034 *$ & $\begin{array}{l}0.998 * \\
\end{array}$ & 0.888 \\
\hline$\left(\right.$ West educ. Sh) ${ }^{2}$ & & & & & & & & & $\begin{array}{c}-1.091^{* *} \\
{[0.518]}\end{array}$ & $\begin{array}{c}-0.999 * \\
{[0.537]}\end{array}$ & $\begin{array}{l}-0.925^{*} \\
{[0.545]}\end{array}$ \\
\hline Age & $\begin{array}{c}-0.218 \\
{[1.338]}\end{array}$ & $\begin{array}{c}-1.304 \\
{[2.022]}\end{array}$ & $\begin{array}{l}-1.109 \\
{[1.943]}\end{array}$ & $\begin{array}{c}0.742 \\
{[1.887]}\end{array}$ & $\begin{array}{c}0.790 \\
{[1.879]}\end{array}$ & $\begin{array}{l}-0.547 \\
{[1.47]}\end{array}$ & $\begin{array}{l}-4.49 \\
{[2.90]}\end{array}$ & $\begin{array}{c}1.45 \\
{[1.60]}\end{array}$ & $\begin{array}{l}-0.0241 \\
{[0.0248]}\end{array}$ & $\begin{array}{c}-0.0245 \\
{[0.0256]}\end{array}$ & $\begin{array}{c}-0.0226 \\
{[0.0263]}\end{array}$ \\
\hline Male & $\begin{array}{c}-16.6 * * * \\
{[5.406]}\end{array}$ & $\begin{array}{c}5.089 \\
{[8.195]}\end{array}$ & $\begin{array}{c}9.435 \\
{[8.239]}\end{array}$ & $\begin{array}{c}-1.858 \\
{[7.466]}\end{array}$ & $\begin{array}{c}1.428 \\
{[7.570]}\end{array}$ & $\begin{array}{c}11.97 * * \\
{[5.93]}\end{array}$ & & & $\begin{array}{c}0.173 * \\
{[0.0998]}\end{array}$ & $\begin{array}{c}0.105 \\
{[0.105]}\end{array}$ & $\begin{array}{l}0.0674 \\
{[0.107]}\end{array}$ \\
\hline Economics & $\begin{array}{c}-0.887 \\
{[5.131]}\end{array}$ & $\begin{array}{c}1.913 \\
{[7.818]}\end{array}$ & $\begin{array}{c}0.334 \\
{[7.610]}\end{array}$ & $\begin{array}{c}-7.210 \\
{[7.315]}\end{array}$ & $\begin{array}{c}-8.118 \\
{[7.287]}\end{array}$ & $\begin{array}{l}10.16^{*} \\
{[5.65]}\end{array}$ & $\begin{array}{c}13.75 \\
{[10.76]}\end{array}$ & $\begin{array}{c}6.68 \\
{[6.03]}\end{array}$ & $\begin{array}{c}0.137 \\
{[0.0923]}\end{array}$ & $\begin{array}{c}0.168^{*} \\
{[0.0936]}\end{array}$ & $\begin{array}{c}0.144 \\
{[0.0969]}\end{array}$ \\
\hline Religious & $\begin{array}{c}7.581 \\
{[7.074]}\end{array}$ & $\begin{array}{c}9.662 \\
{[10.79]}\end{array}$ & $\begin{array}{c}7.775 \\
{[10.46]}\end{array}$ & $\begin{array}{c}14.85 \\
{[9.965]}\end{array}$ & $\begin{array}{c}13.36 \\
{[9.849]}\end{array}$ & $\begin{array}{l}-9.52 \\
{[7.80]}\end{array}$ & $\begin{array}{c}-5.236 \\
{[14.43]}\end{array}$ & $\begin{array}{l}-11.10 \\
{[8.72]}\end{array}$ & $\begin{array}{c}-0.195^{*} \\
{[0.111]}\end{array}$ & $\begin{array}{l}-0.171 \\
{[0.118]}\end{array}$ & $\begin{array}{c}-0.134 \\
{[0.127]}\end{array}$ \\
\hline Work exp. (yrs) & $\begin{array}{l}3.134 * * \\
{[1.508]}\end{array}$ & $\begin{array}{l}4.109^{*} \\
{[2.334]}\end{array}$ & $\begin{array}{c}2.625 \\
{[2.281]}\end{array}$ & $\begin{array}{c}1.435 \\
{[2.054]}\end{array}$ & $\begin{array}{c}0.270 \\
{[2.127]}\end{array}$ & $\begin{array}{c}0.309 \\
{[1.66]}\end{array}$ & $\begin{array}{c}3.945 \\
{[3.898]}\end{array}$ & $\begin{array}{l}-1.18 \\
{[1.60]}\end{array}$ & $\begin{array}{c}0.0280 \\
{[0.0285]}\end{array}$ & $\begin{array}{c}0.0418 \\
{[0.0284]}\end{array}$ & $\begin{array}{c}0.0415 \\
{[0.0287]}\end{array}$ \\
\hline$\%$ sent in $\mathrm{DG}$ & & & $\begin{array}{l}0.57 * * * \\
{[0.185]}\end{array}$ & & $\begin{array}{l}0.334^{*} \\
{[0.180]}\end{array}$ & & & & & & \\
\hline \% invested in $\mathrm{RG}$ & & & $\begin{array}{c}1.177 \\
{[0.769]}\end{array}$ & & & & & & & & $\begin{array}{c}0.019 * * \\
{[0.0096]}\end{array}$ \\
\hline Amt received $\mathrm{TG}$ & & & & $\begin{array}{l}1.16^{* * *} \\
{[0.230]}\end{array}$ & $\begin{array}{l}1.22 * * * \\
{[0.236]}\end{array}$ & & & & & & \\
\hline Self-rank in CG & & & & & & & & & & $\begin{array}{l}0.23 * * * \\
{[0.0666]}\end{array}$ & $\begin{array}{l}0.24 * * * \\
{[0.0675]}\end{array}$ \\
\hline Constant & $\begin{array}{c}39.65 \\
{[28.95]}\end{array}$ & $\begin{array}{c}62.10 \\
{[43.75]}\end{array}$ & $\begin{array}{c}27.05 \\
{[43.22]}\end{array}$ & $\begin{array}{c}-35.38 \\
{[41.62]}\end{array}$ & $\begin{array}{l}-49.63 \\
{[42.49]}\end{array}$ & $\begin{array}{c}52.45 \\
{[31.70]}\end{array}$ & $\begin{array}{c}158.1 * * \\
{[67.0]}\end{array}$ & $\begin{array}{c}9.39 \\
{[33.92]}\end{array}$ & & & \\
\hline Observations & 115 & 115 & 115 & 114 & 114 & 115 & 49 & 66 & 115 & 115 & 115 \\
\hline
\end{tabular}

Standard errors in brackets. $* * * \mathrm{p}<0.01, * * \mathrm{p}<0.05, * \mathrm{p}<0.1$. Columns (1)-(8) report marginal effects from tobit estimations. Columns $(9)-(11)$ report marginal effects from probit estimation. 
Table 4: Competition Game Results by Gender

\begin{tabular}{|c|c|c|c|c|c|c|c|c|}
\hline & $(1)$ & (2) & (3) & (4) & $(5)$ & $(6)$ & $(7)$ & $(8)$ \\
\hline & $\begin{array}{c}\text { Compete } \\
(0 / 1) \\
\text { Male }\end{array}$ & $\begin{array}{c}\text { Compete } \\
(0 / 1) \\
\text { Male } \\
\end{array}$ & $\begin{array}{c}\text { Compete } \\
(0 / 1) \\
\text { Male } \\
\end{array}$ & $\begin{array}{c}\text { Quintile } \\
\text { Belief } \\
\text { Male }\end{array}$ & $\begin{array}{c}\text { Compete } \\
(0 / 1) \\
\text { Female } \\
\end{array}$ & $\begin{array}{c}\text { Compete } \\
(0 / 1) \\
\text { Female } \\
\end{array}$ & $\begin{array}{c}\text { Compete } \\
(0 / 1) \\
\text { Female } \\
\end{array}$ & $\begin{array}{c}\text { Quintile } \\
\text { Belief } \\
\text { Female }\end{array}$ \\
\hline Western educ. share & $\begin{array}{c}0.814 \\
{[0.933]}\end{array}$ & $\begin{array}{c}1.206 \\
{[1.040]}\end{array}$ & $\begin{array}{c}1.158 \\
{[1.073]}\end{array}$ & $\begin{array}{c}-0.682 \\
{[1.916]}\end{array}$ & $\begin{array}{c}1.392 * \\
{[0.720]}\end{array}$ & $\begin{array}{c}1.028 \\
{[0.736]}\end{array}$ & $\begin{array}{c}0.794 \\
{[0.747]}\end{array}$ & $\begin{array}{l}4.098 * * \\
{[1.731]}\end{array}$ \\
\hline (West. educ share) $^{2}$ & $\begin{array}{c}-0.985 \\
{[0.862]}\end{array}$ & $\begin{array}{c}-1.288 \\
{[0.952]}\end{array}$ & $\begin{array}{c}-1.196 \\
{[0.987]}\end{array}$ & $\begin{array}{c}0.137 \\
{[1.759]}\end{array}$ & $\begin{array}{c}-1.426 * * \\
{[0.650]}\end{array}$ & $\begin{array}{c}-1.041 \\
{[0.665]}\end{array}$ & $\begin{array}{c}-0.906 \\
{[0.667]}\end{array}$ & $\begin{array}{c}-3.933 * * \\
{[1.557]}\end{array}$ \\
\hline Self-ranking in CG & & $\begin{array}{l}0.244 * * \\
{[0.106]}\end{array}$ & $\begin{array}{l}0.243 * * \\
{[0.108]}\end{array}$ & & & $\begin{array}{c}0.189 * * \\
{[0.0869]}\end{array}$ & $\begin{array}{l}0.209 * * \\
{[0.0881]}\end{array}$ & \\
\hline Age & $\begin{array}{c}-0.0479 \\
{[0.0409]}\end{array}$ & $\begin{array}{c}-0.0393 \\
{[0.0425]}\end{array}$ & $\begin{array}{l}-0.0303 \\
{[0.0444]}\end{array}$ & $\begin{array}{c}-0.0642 \\
{[0.0849]}\end{array}$ & $\begin{array}{c}0.00265 \\
{[0.0326]}\end{array}$ & $\begin{array}{l}-0.00780 \\
{[0.0340]}\end{array}$ & $\begin{array}{l}-0.0132 \\
{[0.0348]}\end{array}$ & $\begin{array}{c}0.0579 \\
{[0.0758]}\end{array}$ \\
\hline Studied economics & $\begin{array}{c}0.322 * * \\
{[0.140]}\end{array}$ & $\begin{array}{c}0.351 * * \\
{[0.145]}\end{array}$ & $\begin{array}{c}0.335 * * \\
{[0.151]}\end{array}$ & $\begin{array}{r}0.0533 \\
{[0.319]}\end{array}$ & $\begin{array}{c}-0.00899 \\
{[0.120]}\end{array}$ & $\begin{array}{l}0.0327 \\
{[0.121]}\end{array}$ & $\begin{array}{c}0.00836 \\
{[0.125]}\end{array}$ & $\begin{array}{c}-0.204 \\
{[0.283]}\end{array}$ \\
\hline Religious & $\begin{array}{c}-0.102 \\
{[0.201]}\end{array}$ & $\begin{array}{c}-0.0708 \\
{[0.214]}\end{array}$ & $\begin{array}{l}-0.0507 \\
{[0.221]}\end{array}$ & $\begin{array}{c}-0.257 \\
{[0.430]}\end{array}$ & $\begin{array}{c}-0.276 * * \\
{[0.110]}\end{array}$ & $\begin{array}{c}-0.237^{*} \\
{[0.123]}\end{array}$ & $\begin{array}{c}-0.182 \\
{[0.149]}\end{array}$ & $\begin{array}{c}-0.385 \\
{[0.410]}\end{array}$ \\
\hline Work exp. (yrs) & $\begin{array}{c}0.0860 \\
{[0.0566]}\end{array}$ & $\begin{array}{c}0.0963^{*} \\
{[0.0574]}\end{array}$ & $\begin{array}{c}0.0885 \\
{[0.0586]}\end{array}$ & $\begin{array}{l}-0.0230 \\
{[0.116]}\end{array}$ & $\begin{array}{l}0.00333 \\
{[0.0340]}\end{array}$ & $\begin{array}{c}0.0197 \\
{[0.0330]}\end{array}$ & $\begin{array}{c}0.0252 \\
{[0.0335]}\end{array}$ & $\begin{array}{c}-0.136 * \\
{[0.0768]}\end{array}$ \\
\hline$\%$ invested in $\mathrm{RG}$ & & & $\begin{array}{c}0.0171 \\
{[0.0143]}\end{array}$ & & & & $\begin{array}{c}0.0214 \\
{[0.0137]}\end{array}$ & \\
\hline Observations & 49 & 49 & 49 & 49 & 66 & 66 & 66 & 66 \\
\hline
\end{tabular}


Table 5: Selection Effects: Marginal Effects of Western Education Share

\begin{tabular}{|c|c|c|c|c|c|}
\hline \multirow{3}{*}{ Sample: } & \multicolumn{5}{|c|}{ education share) } \\
\hline & \multicolumn{2}{|c|}{ Arrived age $<=15$ years } & \multicolumn{2}{|c|}{ Arrived $>15$ years } & \multirow[t]{3}{*}{$\begin{array}{c}\text { t-test } \\
\text { (p-value) }\end{array}$} \\
\hline & \multicolumn{2}{|c|}{ Coefficient on: } & \multicolumn{2}{|c|}{ Coefficient on: } & \\
\hline Game: & $\mathrm{X}$ & $\mathrm{X}^{2}$ & & & \\
\hline Dictator Game & $-18 * *$ & - & -24 & - & 0.69 \\
\hline Trust Game - Sender & $-35 * *$ & - & -23 & - & 0.59 \\
\hline Trust Game - Receiver & $-25 * *$ & - & -32 & - & 0.72 \\
\hline Risk Game & 9.07 & - & 17.3 & - & 0.61 \\
\hline - Male & -24.5 & - & -9.17 & - & 0.57 \\
\hline - Female & $24.7 * *$ & - & 37.7 & . & 0.51 \\
\hline Competition Game & 0.67 & -0.77 & 0.35 & 0.45 & 0.28 \\
\hline - Male & 0.19 & 0.80 & -0.60 & 0.83 & 0.39 \\
\hline - Female & $2.24 *$ & $-2.14^{*}$ & 2.38 & -4.70 & 0.40 \\
\hline $\mathrm{N}$ & \multicolumn{2}{|c|}{46} & \multicolumn{2}{|c|}{73} & \\
\hline
\end{tabular}

Table 6: Correlations between Survey and Experimental Measures

\begin{tabular}{lcc}
\hline & $\begin{array}{c}\text { Most people } \\
\text { can be trusted }\end{array}$ & $\begin{array}{c}\text { Generally people } \\
\text { try to be helpful }\end{array}$ \\
\cline { 2 - 3 } Most people can be trusted & 1.0 & 1.0 \\
Generally people try to be helpful & 0.19 & 0.23 \\
\% sent in Dictator Game & 0.03 & 0.06 \\
\% sent in Trust Game & 0.12 & 0.13 \\
\% returned in Trust game & -0.03 & -0.06 \\
\% invested in Risk game & -0.04 & 0.05 \\
Choose to compete & 0.04 & \\
\hline
\end{tabular}


Table 7: Relationship between Survey-based Measures and Western Education Share

\begin{tabular}{lcc}
\hline Dependent Variable: & $\begin{array}{c}(1) \\
\text { Most people can } \\
\text { be trusted }\end{array}$ & $\begin{array}{c}(2) \\
\text { People try and } \\
\text { be helpful }\end{array}$ \\
\hline western education & 0.097 & -0.112 \\
share & {$[0.162]$} & {$[0.160]$} \\
age & -0.023 & -0.013 \\
male & {$[0.023]$} & {$[0.023]$} \\
& 0.065 & 0.062 \\
economics student & {$[0.093]$} & {$[0.090]$} \\
religious & -0.030 & -0.003 \\
& {$[0.090]$} & {$[0.089]$} \\
work experience & 0.187 & 0.051 \\
& {$[0.105]$} & {$[0.119]$} \\
$\mathrm{N}$ & 0.014 & 0.071 \\
Standard errors in brackets. & {$[0.027]$} & {$[0.032]^{* *}$} \\
estimation. & 114 & 113 \\
\hline
\end{tabular}


Table A1: Summary Statistics

\begin{tabular}{lccccc}
\hline & & & & & \\
& $N$ & Mean & Std. Dev. & Min. & Max. \\
\cline { 2 - 5 } Age & 119 & 21.3 & 2.3 & 18 & 29 \\
Male & 120 & 43.3 & 0.49 & 0 & 1 \\
Economics student & 120 & 58.3 & 0.50 & 0 & 1 \\
Religious & 120 & 16.7 & 0.37 & 0 & 1 \\
Years of work experience & 116 & 1.83 & 2.10 & 0 & 10.1 \\
Share of education in the west & 120 & 0.45 & 0.37 & 0 & 1 \\
Think of oneself as Australian & 120 & 2.67 & 1.40 & 1 & 5 \\
Age moved to Australia & 119 & 14.3 & 7.5 & 0.002 & 1 \\
Share of life lived in Australia & 119 & 0.33 & 0.34 & 0 & 28 \\
& & & & & \\
\hline
\end{tabular}

Table A2: Extent to which agree with: “In many ways I think of myself as Australian.”

Strongly Agree

Agree

Neutral

Disagree

Strongly Disagree

\begin{tabular}{cc}
$\mathrm{N}$ & $\%$ \\
\hline 31 & 25.8 \\
33 & 27.5 \\
18 & 15.0 \\
21 & 17.5 \\
17 & 14.2
\end{tabular}

